\title{
Comparison of the Effect of Melissa officinalis Capsule and Care Educational Programs on the Intensity of Physical, Mental and Social Symptoms of Premenstrual Syndrome in High School Female Students
}

\author{
Marzieh Akbarzadeh ${ }^{*}$, Zinab Moshfeghy ${ }^{2}$, Mansureh Dehghani ${ }^{3}$, Masoumeh Emamghoreishi ${ }^{4}$, Pouran \\ Tavakoli $^{5}$, Najaf Zare ${ }^{6}$
}

\begin{abstract}
Objectives: Premenstrual syndrome (PMS) is one of the psychosomatic problems related to women $s$ reproductive function, which is associated with emotional and mood symptoms such as anger, anxiety and irritability. The current study aimed to compare the effect of Melissa officinalis capsule and care educational programs on the intensity of physical, mental and social aspects of PMS in high school girls.

Materials and Methods: This study was a randomized, placebo-controlled trial which was conducted on 200 high school girls with PMS who were randomly allocated into 4 groups in Shiraz. The first group received $600 \mathrm{mg}$ of $M$. officinalis essence daily from the first to the end day of their menstrual cycle for 3 consecutive cycles; the second and third groups received care educational program and placebo respectively, and the last one was the control group. The data were analyzed using paired $t$ test and Repeated measures analysis of variance (ANOVA).

Results: The results of repeated measures ANOVA test revealed a significant reduction in 3 determined times, pre-intervention, one and 2 consecutive months after the intervention $(P<0.001)$, in the intensity of physical, psychological and social aspects of PMS symptoms, and this varied in different groups $(P<0.001)$. The extent of changes varied over time and in different groups, so, the control and placebo groups had the least symptom changes over the time

Conclusion: Melissa officinalis capsule and care educational programs were much more effective in reduction of the severity of physical, mental and social symptoms of PMS compared to the control and placebo groups.

Keywords: Premenstrual syndrome, Melissa officinalis, Physical, Mental, Education, Student
\end{abstract}

\section{Introduction}

Premenstrual syndrome (PMS) is one of the psychosomatic problems related to women's reproductive function, which is associated with emotional and mood disorders such as anger, anxiety and irritability (1). PMS is a periodic event in which a combination of corporeal, neurological and psychiatric disorders cause disturbance in individual's social adaptation, interpersonal relationships and normal activities, which negatively affects the quality of her life (2). It has been revealed that this syndrome is identified with more than 150 physical and mental signs and symptoms. Its psycho-mental symptoms, including the decline in interest in doing usual activities, difficulty concentrating, nervousness, irritability, interpersonal conflicts, anxiety, feelings of pressure (stress), emotional instability, depressed mood, feelings of hopelessness, and self-criticism (3). The key element of a PMS diagnosis as identified by ACOG (American College of Obstetrics and Gynecology) is the presence of at least one somatic and emotional symptom before menstruation, which will be diminished by menstruation occurrence without medical interventions (4). The International Classification of Diseases (ICD) places premenstrual tension as the lay term that is used for PMS under "Diseases of the genitourinary system" (5). This disorder can cause disturbance in marital relationships, maternal-child challenges, social isolation, school and work absenteeism, poor performance, attention deficits, increase in psychosomatic complaints, and even suicide and legal problems (6)

Petta et al in their study on 1053 women (between 18 to 40 years old) reported irritability, anxiety, anger, aggression, mood swings and crying as the most common mental symptoms (7). About $90 \%$ of women report some suffering from pre-menstrual symptoms in a number of

Received 14 December 2016, Accepted 26 March 2017, Available online 4 April 2017

${ }^{1}$ Maternal-Fetal Medicine Research Center, Department of Midwifery, School of Nursing and Midwifery, Shiraz University of Medical Sciences, Shiraz, Iran. ${ }^{2}$ Community Based Psychiatric Care Research Center, Department of Midwifery, School of Nursing and Midwifery, Shiraz University of Medical Sciences, Shiraz, Iran. ${ }^{3}$ School of Nursing and Midwifery, Shiraz University of Medical Sciences, Shiraz, Iran. ${ }^{4}$ Department of Pharmacology, School of Medicine, Shiraz University of Medical Sciences. ${ }^{5}$ Department of Nursing, School of Nursing and Midwifery, Shiraz University of Medical Sciences, Shiraz, Iran. ${ }^{6}$ Infertility Research Center, School of Medicine, Department of Biostatistics, Shiraz University of Medical Sciences, Shiraz, Iran.

*Corresponding Author: Marzieh Akbarzadeh, Tel: +98711-6474250, Fax: +98711-647425, Email: akbarzadm@sums.ac.ir 
their cycles. The relationship between PMS and depression can be classified as mild, moderate and severe. The severe depression prevalence has been reported $11.3 \%$ among women, and its moderate one is $24.6 \%$. Consumption of alcohol, contraceptives, drugs and a history of depression have relationship with severe depression (8). About 22.9\% of those with severe PMS syndrome deal with psychomental disorders (9). A study was conducted to examine the negative effects of PMS syndrome and its related factors on their lives; the samples were from 14 different countries such as France, Germany, Italy, Spain, Hungary, Turkey, Brazil, Mexico, Hong Kong, Pakistan, Thailand, Japan, Korea, and Australia. The analysis of data revealed that their quality of life is not dependent on the country and its culture, but their amount of knowledge about the symptoms can be so impressive in this regard (10). Although PMS is not fatal, it can affect many aspects of a person's life and can lead to lack of efficiency and disability.

According to the tenth international classification of mental, behavioral and development disorders, PMS syndrome is categorized as a component of women's medical disorders (not mental disorders) which are stated as a transient condition of disorders at a certain time, just before menstruation (11). It is difficult to estimate the true prevalence of this common disorder among women because of the cultural and social differences, various diagnostic tools and criteria, as well as differences in defining the target population (12). Over $80 \%$ of women experience one of the PMS syndrome symptoms (13), and about 5 to $8 \%$ suffer from the intense one (14). The prevalence of PMS syndrome has been reported in Italy, Thailand, Turkey and Brazil as 48\%, 25\%, $61.4 \%$ and $7.25 \%$, respectively (15). A recent study which was conducted in Iran revealed that all adolescents who were studied (100\%) experienced at least one premenstrual symptom with different intensities (moderate to very severe), and approximately 83\% (118) of them had PMS syndrome according to ACOG criteria (16). Although the etiology of PMS is not clear, there are distinct attributive theories in this regard, including hormonal imbalance, hypoglycemia, hyperprolactinemia, psychological reasons, endorphin reduction, asymptomatic ovarian infection, lack of essential fatty acids and vitamins, acidbase disturbance, prostaglandin imbalance, and mineral deficiency (17). Some other studies also stated biological, psychological and socio-cultural reasons in this regard (18). The changes in the level of estrogen, progesterone, androgens and prolactin were considered more important in the PMS syndrome etiology, and brain serotonin production has particularly the central role in this issue (19). Different methods are recommended for relief from this syndrome. Although non-medical and psychological interventions have been suggested to women with various types of disorders, no regular review study has been conducted in this respect (20). Basically, the purpose of PMS treatment is to suppress or decrease the symptoms and its devastating impacts on their functions, personal relationships, which leads to improvement in their quality of life (21).

Due to the lack of study on the use of herbal medicine in reducing PMS syndrome, it seems necessary to do some research in this field. This study aimed to explore the effects of both $M$. officinalis capsule and care educational programs on the intensity of psychological symptoms of PMS in high school female students.

\section{Materials and Methods}

This study is a randomized clinical trial in which the intensities of PMS symptoms are compared in 4 female groups. The study population consisted of all high-school students who met the inclusion criteria across 4 districts of the city. High schools were picked up randomly across various districts, and subjects were selected from each school by random cluster sampling. Considering the effect size of 2 (reflecting the difference between the two groups), standard deviation (SD) of 1.3, type-I error probability of $5 \%$, and power of 0.9 , it was estimated that 50 subjects were needed in each group (considering a possible attrition rate of $20 \%$ ). Therefore, we needed 200 subjects as total sample size.

The inclusion criteria of the study were being willing to participate in the study being a high-school student, studying in the high-schools of 4 educational districts in Shiraz, not using vitamin supplements during the study, not having used hormonal drugs, such as oral contraceptive pills, at least two months prior to the study, having a menstrual cycle length of 24 to 35 days, not suffering from underlying diseases, such as thyroid and diabetes, and mental disorders, and completing written informed consent, general health questionnaire, and Premenstrual Syndrome Screening Tool (PSST). On the other hand, the exclusion criteria of the study were lack of willingness to continue participation in the study, parents' request for exclusion of their children from the study; experiencing a stressful accident such as death, marriage, or surgery throughout the study, changes in the intervals of menstrual cycles of less than 24 and more than 35 days, and changes in the length of menstrual cycles for less than 3 and more than 7 days.

The study population consisted of all high-school students who were selected from 4 educational districts in Shiraz. About 800 students were selected through random cluster sampling after approval under the supervision of the education department of Shiraz University of Medical Sciences. The permission form was asked to be written by all students with inclusion criteria and their parents. Then, all the subjects completed demographic questionnaire, PMS screening tool and General Health Questionnaire at the beginning of the study. However, the PSST questionnaire was refilled during one consecutive month. Finally, 200 subjects who obtained a score less than 23 in the General Health Questionnaire (GHQ) (22- 
24), and a score higher than 20 in the PSST (25-26) were selected to be randomly allocated into 4 groups $(n=50)$. Subjects in the first, second and third groups were required to receive $M$. officinalis capsule, care educational program and placebo respectively and the fourth group was the control group.

Intervention

1. Melissa officinalis capsules which contain M. officinalis powder were made in Shiraz Medical School under the supervision of a professional counselor. Each capsule contained $600 \mathrm{mg}$ of the M. officinalis essence which was prescribed twice a day $(1200 \mathrm{mg} / 24 \mathrm{~h})$ from the first to the last day of their menstrual cycle for 3 consecutive cycles.

To determine the dose of $M$. officinalis capsule according to previous researches conducted by the other researcher, we found no previous study conducted on the effects of M. officinalis on the symptoms of PMS. However, the symptoms of stress and depression have been studied in animal and human studies. In a study by Kort et al it was suggested that cinnamon supplementation improves menstrual cyclicity (27). Given that the plant powder is used in our study, two tablets of $600 \mathrm{mg}$ daily were proposed by project advisor.

2. Training program was scheduled for 6 sessions of 2 hours in the education group, which were held twice a week. Its content included the importance of adolescence, education about menstrual cycle and PMS, its prevalence, diagnosis and various treatment strategies, relaxation and imagery training, stress management, stress effects on PMS, the beneficial roles of changing diet, and doing exercise during this period.

3. The placebo group was designed as M. officinalis counterpart control group. This placebo, starch capsule, prepared in Shiraz Medical School under the supervision of a professional counselor was similar to $M$ officinalis in shape and route of consumption.

4. The last group was considered as the counterpart control group of those who attended the educational program. Students did not receive allocated intervention in this group except for prepared educational pamphlet for the control group at the end of the study.

To prevent any possible errors, the research assistant encoded the completed questionnaires. According to research ethics, the subjects in the intervention group had the right to be excluded from the study if they decided. The researcher contacted the participants at least 3-4 times to re-explain the care points, medicine administration route and additional information in this regard. PMS screening questionnaire assessed the pre-menstruation symptoms before and then in three consecutive months ( 3 menstrual cycle) after the intervention.

The PSST consists of 19 items in 2 sections. The first section includes 14 items on physical, mood and behavioral symptoms, and the second section contains 5 items that assess the effects of symptoms on the subject's life. Each item is responded on a four-point Likert scale including none, mild, average, and severe, receiving a score from 0 to 3 , respectively.

Thus, the minimum and maximum scores of the questionnaire are 0 and 57 . Scores ranging from 0 to 19,20 to 38 , and 39 to 57 represented mild, average, and severe conditions, respectively. Those who gained scores higher than 20 were enrolled in the current study.

\section{Statistical Methods}

Data were analyzed through applying SPSS software version 11.5 as follows:

1) The repeated measures ANOVA was used to assess the trend of changes in PMS symptoms at different times and compared the changes in each group. 2) Moreover, paired $t$ test was used to compare the changes of PMS scores in each group before and after the intervention. 3) Chi-square was applied to compare the qualitative variables in 4 groups.

\section{Results}

The mean age of the participants was $16.2 \pm 1.06$ years in the intervention group and $16.3 \pm 0.66$ years in the placebo group. The two groups were homogeneous with respect to age $(P=0.32)$, education level $(P=0.83)$, and body mass index $(\mathrm{BMI})(P=0.42)$. Demographic characteristics are shown in Table 1.

The results reveal a significant relationship in psychological symptoms (Table 2) and physical symptoms of PMS syndrome (Table 3 ) just before its occurrence and then in 3 consecutive months (three menstrual cycle) after

Table 1. Mean Age of the Study Population in Different Groups

\begin{tabular}{|c|c|c|c|c|c|}
\hline Age Education & $\begin{array}{c}\text { Melissa officinalis } \\
\text { No. (\%) }\end{array}$ & $\begin{array}{l}\text { Placebo } \\
\text { No. (\%) }\end{array}$ & $\begin{array}{l}\text { Education } \\
\text { No. (\%) }\end{array}$ & $\begin{array}{l}\text { Control } \\
\text { No. (\%) }\end{array}$ & $P$ Value \\
\hline $14-16$ & $22(44)$ & $30(60)$ & $25(50)$ & $24(24)$ & Chi-square, $P=0.427$ \\
\hline $16-18$ & $28(56)$ & $20(40)$ & $25(50)$ & $26(52)$ & \\
\hline Total & $50(100)$ & $50(100)$ & $50(100)$ & $50(100)$ & \\
\hline Class 1 & $14(28)$ & $10(20)$ & $10(20)$ & $15(30)$ & \\
\hline Class 2 & $15(30)$ & $13(26)$ & $12(24)$ & $15(30)$ & Chi-square, $P=0.833$ \\
\hline Class 3 & $13(26)$ & $14(28)$ & $14(28)$ & $11(22)$ & \\
\hline Class 4 & $8(16)$ & $13(26)$ & $14(28)$ & $9(18)$ & \\
\hline Total & $50(100)$ & $50(100)$ & $50(100)$ & $50(100)$ & \\
\hline
\end{tabular}


Table 2. Comparison of Emotional Symptoms of Premenstrual Syndrome Before, 1 Month, 2 Months and 3 Months After the Intervention

\begin{tabular}{|c|c|c|c|c|c|c|}
\hline Time & Group & Number & Mean \pm SD & Upper Bound & Lower Bound & \multirow{6}{*}{$\begin{array}{c}\boldsymbol{P} \text { Value } \\
\text { Repeated measurement } \\
\text { Time: } \\
\mathrm{F}=22.70, d f=2, P<0.001 \\
\text { Group: } \\
\mathrm{F}=6.161, d f=3, P=0.001\end{array}$} \\
\hline \multirow{5}{*}{ Before intervention } & Education & 50 & $13.66 \pm 4.47$ & 3 & 24 & \\
\hline & Control & 50 & $18.82 \pm 4.78$ & 3 & 24 & \\
\hline & Melissa officinalis capsule & 45 & $14.2 \pm 3.85$ & 3 & 24 & \\
\hline & Placebo & 46 & $11.8 \pm 4.42$ & 3 & 24 & \\
\hline & Total & 191 & $12.78 \pm 4.49$ & 3 & 24 & \\
\hline \multirow{5}{*}{$\begin{array}{l}1 \text { month after } \\
\text { intervention }\end{array}$} & Education & 50 & $11.24 \pm 2.60$ & 7 & 17 & \\
\hline & Control & 50 & $11.94 \pm 3.84$ & 3 & 19 & \\
\hline & Melissa officinalis capsule & 45 & $12.5 \pm 2.97$ & 6 & 19 & \\
\hline & Placebo & 46 & $10.62 \pm 4.04$ & 3 & 33 & \\
\hline & Total & 191 & $11.57 \pm 3.46$ & 3 & 23 & \\
\hline \multirow{5}{*}{$\begin{array}{l}2 \text { months after } \\
\text { intervention }\end{array}$} & Education & 50 & $15.04 \pm 3.92$ & 10 & 24 & \\
\hline & Control & 50 & $12.70 \pm 4.94$ & 3 & 24 & \\
\hline & Melissa officinalis capsule & 45 & $15.02 \pm 3.32$ & 10 & 24 & \\
\hline & Placebo & 46 & $11.82 \pm 4.99$ & 3 & 24 & \\
\hline & Total & 191 & $13.64 \pm 4.54$ & 3 & 24 & \\
\hline \multirow{5}{*}{$\begin{array}{l}3 \text { months after } \\
\text { intervention }\end{array}$} & Education & 50 & $15.04 \pm 3.64$ & 3 & 24 & \\
\hline & Control & 50 & $12.70 \pm 2.33$ & 7 & 24 & \\
\hline & Melissa officinalis capsule & 45 & $15.02 \pm 3.78$ & 2 & 24 & \\
\hline & Placebo & 46 & $11.82 \pm 3.65$ & 6 & 24 & \\
\hline & Total & 191 & $13.64 \pm 2.63$ & 2 & 24 & \\
\hline
\end{tabular}

Table 3. Comparison of Emotional Symptoms of Premenstrual Syndrome Before, 1 Month, 2 Months and 3 Months After the Intervention

\begin{tabular}{|c|c|c|c|c|c|c|}
\hline Time & Group & Number & Mean \pm SD & Upper Bound & Lower Bound & \multirow{6}{*}{$\begin{array}{c}\boldsymbol{P} \text { Value } \\
\text { Repeated measurement } \\
\text { Time: } \\
\mathrm{F}=18.29, d f=2, P<0.001 \\
\text { Group: } \\
\mathrm{F}=18.83, d f=3, P<0.001\end{array}$} \\
\hline \multirow{5}{*}{ Before intervention } & Education & 50 & $12.52 \pm 3.98$ & 4 & 19 & \\
\hline & Control & 50 & $9.38 \pm 2.89$ & 3 & 15 & \\
\hline & Melissa officinalis capsule & 50 & $14.2 \pm 2.81$ & 6 & 19 & \\
\hline & Placebo & 50 & $9.6 \pm 2.60$ & 4 & 15 & \\
\hline & Total & 200 & $11.43 \pm 3.89$ & 3 & 19 & \\
\hline \multirow{5}{*}{$\begin{array}{l}1 \text { month after } \\
\text { intervention }\end{array}$} & Education & 50 & $10.62 \pm 2.31$ & 6 & 18 & \\
\hline & Control & 50 & $9.52 \pm 3.12$ & 5 & 18 & \\
\hline & Melissa officinalis capsule & 45 & $11.2 \pm 1.47$ & 8 & 15 & \\
\hline & Placebo & 46 & $2.92 \pm 3.33$ & 3 & 18 & \\
\hline & Total & 191 & $10.31 \pm 2.72$ & 3 & 18 & \\
\hline \multirow{5}{*}{$\begin{array}{l}2 \text { months after } \\
\text { intervention }\end{array}$} & Education & 50 & $12.94 \pm 3.83$ & 6 & 18 & \\
\hline & Control & 50 & $10.60 \pm 3.52$ & 5 & 18 & \\
\hline & Melissa officinalis capsule & 45 & $12.52 \pm 2.44$ & 9 & 18 & \\
\hline & Placebo & 46 & $10.06 \pm 3.55$ & 3 & 18 & \\
\hline & Total & 191 & $11.39 \pm 3.56$ & 2 & 18 & \\
\hline \multirow{5}{*}{$\begin{array}{l}3 \text { months after } \\
\text { intervention }\end{array}$} & Education & 50 & $15.04 \pm 3.64$ & 3 & 18 & \\
\hline & Control & 50 & $10.66 \pm 3.34$ & 3 & 18 & \\
\hline & Melissa officinalis capsule & 45 & $12.44 \pm 2.54$ & 6 & 18 & \\
\hline & Placebo & 46 & $12.34 \pm 3.65$ & 6 & 18 & \\
\hline & Total & 191 & $10.61 \pm 3.23$ & 3 & 18 & \\
\hline
\end{tabular}

the intervention in different study groups in regard to the time, group and time-group effects.

Measurements of Physical and psychological symptoms in 3 determined times, i.e. before, one and two months after the intervention, imply a decreasing trend throughout time $(P<0.001)$. The symptoms varied in different groups $(P<0.001)$. Furthermore, the effect of time and group types was different overtime. However, the control group had the least effect, indicating the efficiency of $M$. officinalis capsule and educational course.
Comparing the social symptoms of PMS at determined times (before, one to three consecutive months after the intervention) was significant for different groups in regard to the time, group and time/groups effect $(P<0.001)$ (Table 3).

Comparing all (physical, psychologic and social) symptoms of PMS syndrome before and three consecutive months after the intervention we found significant differences in all groups in regard to the time and group type $(P<0.001$; Table 4$)$. 
Table 4. Comparison of Social Symptoms of Premenstrual Syndrome Before, 1 Month, 2 Months and 3 Months After the Intervention

\begin{tabular}{|c|c|c|c|c|c|c|}
\hline Time & Group & Number & Mean \pm SD & Upper Bound & Lower Bound & \multirow{6}{*}{$\begin{array}{c}\boldsymbol{P} \text { Value } \\
\text { Repeated measurement } \\
\text { Time: } \\
\mathrm{F}=11.023, d f=2, P<0.001 \\
\text { Group: } \\
\mathrm{F}=18.83, d f=3, P=0.001\end{array}$} \\
\hline \multirow{5}{*}{ Before intervention } & Education & 50 & $13.54 \pm 3.93$ & 5 & 18 & \\
\hline & Control & 50 & $8.02 \pm 3.93$ & 0 & 15 & \\
\hline & Melissa officinalis capsule & 45 & $13.34 \pm 2.69$ & 7 & 19 & \\
\hline & Placebo & 46 & $8.26 \pm 2.31$ & 2 & 15 & \\
\hline & Total & 191 & $10.79 \pm 3.12$ & 0 & 19 & \\
\hline \multirow{5}{*}{$\begin{array}{l}1 \text { month after } \\
\text { intervention }\end{array}$} & Education & 50 & $10.62 \pm 1.47$ & 6 & 18 & \\
\hline & Control & 50 & $9.52 \pm 3.33$ & 5 & 18 & \\
\hline & Melissa officinalis capsule & 45 & $11.2 \pm 2.72$ & 5 & 15 & \\
\hline & Placebo & 46 & $9.92 \pm 3.01$ & 3 & 18 & \\
\hline & Total & 191 & $10.31 \pm 3.52$ & 3 & 18 & \\
\hline \multirow{5}{*}{$\begin{array}{l}2 \text { months after } \\
\text { intervention }\end{array}$} & Education & 50 & $13.56 \pm 2.47$ & 5 & 19 & \\
\hline & Control & 50 & $10.06 \pm 3.68$ & 3 & 15 & \\
\hline & Melissa officinalis capsule & 45 & $14.14 \pm 4.04$ & 6 & 19 & \\
\hline & Placebo & 46 & $9.1 \pm 3.34$ & 3 & 15 & \\
\hline & Total & 191 & $11.5 \pm 4.54$ & 3 & 19 & \\
\hline \multirow{5}{*}{$\begin{array}{l}3 \text { months after } \\
\text { intervention }\end{array}$} & Education & 50 & $10.33 \pm 2.77$ & 3 & 18 & \\
\hline & Control & 50 & $12.70 \pm 4.68$ & 3 & 19 & \\
\hline & Melissa officinalis capsule & 45 & $12.30 \pm 2.55$ & 3 & 18 & \\
\hline & Placebo & 46 & $11.82 \pm 2.33$ & 3 & 18 & \\
\hline & Total & 191 & $10.67 \pm 3.92$ & 3 & 19 & \\
\hline
\end{tabular}

Table 5. Comparison of Total Score of Premenstrual Syndrome Before, 1 Month, 2 Months and 3 Months After the Intervention

\begin{tabular}{|c|c|c|c|c|c|c|}
\hline Time & Group & Number & Mean \pm SD & Upper Bound & Lower Bound & \multirow{6}{*}{$\begin{array}{c}P \text { Value } \\
\text { Repeated measurement } \\
\text { Time: } \\
\mathrm{F}=73.092, d f=3, P<0.001 \\
\text { Group: } \\
\mathrm{F}=8.73, d f=3, P<0.001\end{array}$} \\
\hline \multirow{5}{*}{ Before intervention } & Education & 50 & $37.94 \pm 15.85$ & 7 & 57 & \\
\hline & Control & 50 & $38.02 \pm 16.25$ & 2 & 57 & \\
\hline & Melissa officinalis capsule & 45 & $42.56 \pm 15.73$ & 2 & 57 & \\
\hline & Placebo & 46 & $39.28 \pm 16.2$ & 2 & 57 & \\
\hline & Total & 191 & $39.45 \pm 16.003$ & 2 & 57 & \\
\hline \multirow{5}{*}{$\begin{array}{l}1 \text { month after } \\
\text { intervention }\end{array}$} & Education & 50 & $28.26 \pm 12.55$ & 7 & 57 & \\
\hline & Control & 50 & $33.76 \pm 14.07$ & 6 & 57 & \\
\hline & Melissa officinalis capsule & 45 & $30.72 \pm 13.24$ & 2 & 57 & \\
\hline & Placebo & 46 & $35.24 \pm 13.66$ & 6 & 57 & \\
\hline & Total & 191 & $31.91 \pm 13.571$ & 2 & 57 & \\
\hline \multirow{5}{*}{$\begin{array}{l}2 \text { months after } \\
\text { intervention }\end{array}$} & Education & 50 & $28.78 \pm 12.12$ & 7 & 54 & \\
\hline & Control & 50 & $33.1 \pm 13.28$ & 6 & 57 & \\
\hline & Melissa officinalis capsule & 45 & $30.02 \pm 12.08$ & 2 & 57 & \\
\hline & Placebo & 46 & $34.44 \pm 12.71$ & 6 & 57 & \\
\hline & Total & 191 & $31.33 \pm 12.73$ & 2 & 57 & \\
\hline \multirow{5}{*}{$\begin{array}{l}3 \text { months after } \\
\text { intervention }\end{array}$} & Education & 50 & $11.3 \pm 10.07$ & 2 & 52 & \\
\hline & Control & 50 & $28.1 \pm 18.57$ & 2 & 57 & \\
\hline & Melissa officinalis capsule & 45 & $13.90 \pm 10.22$ & 2 & 57 & \\
\hline & Placebo & 46 & $28.38 \pm 18.33$ & 2 & 57 & \\
\hline & Total & 191 & $20.42 \pm 16.75$ & 2 & 57 & \\
\hline
\end{tabular}

\section{Discussion}

Although the exact cause of PMS is unknown, there are some accepted theories about its root in the excessive reduction of serotonin and dopamine in the blood. Therefore, treatment to reduce the symptoms must be planned to increase the amount of neurotransmitters in the central nervous system.

The findings of the present study which was designed to compare the effects of care educational program, $M$. officinalis administration, placebo and control group well demonstrated that severity of the symptom in those who received $M$. officinalis was significantly different from the placebo at different stages.

Since there was no study about $M$. officinalis's impact on PMS severity, in this study we compared its impact with other drugs. M. officinalis's positive impact on anxiety, depression, sleep disorders and stress, which are some of PMS syndrome symptoms, has been proven in other studies. The study showed that it increased the efficacy, tolerability and decreased concentration problems and impulsiveness in children less than 12 years of age with restlessness and insomnia (28). 
Melissa officinalis capsules (600 mg) were effective in improving the negative effects of stress, leading to a significant increase in relief (29). It has been shown that the combination of M. officinalis and Valeriana officinalis has anxiolytic properties, and should be further explored (30).

Van Die et al studied the effects of a combination of Hypericum perforatum and Vitex agnus-castus on PMSlike symptoms in late perimenopausal women. Results showed significant reductions in anxiety, hydration, depression and crying in the intervention group than the control group. The follow-up of the subjects revealed a reduction in symptoms 5 weeks after the intervention $(P<0.005)(31)$.

In this study, the drug was used for 4 cycles, and its result for symptoms reduction was consistent with the findings of our study, but there was a difference in that van Die et al used Abrahams Menstrual Symptoms Questionnaire and the intervention lasted longer than this study. In this study, the largest decline in symptoms was only one month after the intervention.

Khayat et al studied the effect of treatment with ginger on the severity of PMS symptoms in 70 students in Tehran. Doses of ginger and placebo were $250 \mathrm{mg} / 12 \mathrm{~h}$ and were given from 7 days before until 3 days after the onset of menstrual bleeding. Studies have shown that ginger can modulate the prostaglandins system due to its constituent known as Gingerol, so, it is effective in reduction of the severity of mood and physical and behavioral symptoms of PMS (32).

These study results are consistent with those of the study by Khayat et al. However, we could assess their social symptoms after the intervention by the PMS screening questionnaire, which reveals the effects of $M$. officinalis on mood, behavior and physical symptoms besides their social functioning.

Another study has compared the chamomile extract and mefenamic acid on the reduction of PMS symptom. Data analysis demonstrates chamomile effectiveness in their emotional symptoms $(P<0.001)$ despite its lower impact on physical symptoms $(P>0.005)$. On the other hand, this study implies the positive effect of $M$. officinalis on their physical, psychological and social aspects (33).

In a study, Cases et al used M. officinalis L. leaf in treating volunteers with mild to moderate anxiety disorders and sleep disorders and reported that the anxiety manifestation and insomnia decreased from $18 \%$ to $42 \%$ and $95 \%$ of the samples had responded to treatment (34).

The results of the current study showed that $M$ officinalis capsules were more effective in reducing the intensity of PMS symptoms the first 3 months after the intervention compared to before it. Principal mechanism of $M$. officinalis in PMS symptom reduction is perhaps related to serotonin reuptake as serotonin imbalance is the main cause of PMS (35).

Serotonin is a natural sedative contributing to well- being, happiness and euphoria (36). Its lower level is associated with poor function of the brain in the central part. The researchers concluded that it was more difficult for the brain to control emotional responses than anger if it occurs (37).

Many antidepressants are administered to increase the serotonin levels in the synapses. Selective serotonin reuptake inhibitors (SSRIs) are the typical examples in this regard which increase the level of neurotransmitters in the central nervous system. Thus, it is possible that serotonin reduction is the main reason for depression (38-41).

It seems that the main effect of $M$. officinalis in this study was its increasing impact on serotonin levels since it plays an important role in controlling the sexual behavior, mood, sleep, pain, appetite, aggressive power, cardiovascular system and gastrointestinal peristalsis (42). The researchers also report that the increase in dopamine has been effective in improving the symptoms of PMS (43).

Most neuro-chemical studies have focused on the effects of serotonin, not epinephrine, as anxiety reducer. Medications can apply anxiety relieving effects by changing these neurotransmitters level in the brain or interrupting the actions of their receptors (44-45).

It seems that Melissa increases the amount of central serotonin and dopamine in the serotonergic systems to reduce the symptoms of this syndrome. It also affects the gamma-aminobutyric acid receptor.

Its main components are citral, linalool, geraniol, $\beta$-caryophyllene oxide, phenolic acid, tannins, rosmarinic acid and caffeic acid, which increase the GABA transmission contributing to the reduction of anxiety and its associated symptoms in addition to insomnia (34).

Cases et al investigated the mechanism of action of $M$. officinalis in anxiety disorders and sleep disorders. It has been argued that "the GABAergic system is a logical and promising target for new strategies to prevent and treat anxiety and its associated symptoms, such as restlessness and insomnia. GABA activity is mediated through GABAA and GABAB receptor-dependent inhibition of the CNS, and GABA catabolism relies on GABA transaminase (GABA-T) levels" (34). In addition, in our study no side effect was observed regarding taking $M$. officinalis capsules, which in line with other studies.

The results of the paired $t$ test and repeated measures analysis also indicated a significant difference in the intensity of symptoms at different stages in the intervention group than in the placebo group. In a study by Joao et al, the findings about the efficacy of educational programs in the girls' PMS were consistent with our study results and the only difference was the use of Abraham questionnaire (46).

Hunter et al did a study on a randomized comparison of psychological (cognitive behavior therapy), medical (fluoxetine) and combined treatment in women with premenstrual dysphonic disorder; it was shown that there appears to be no additional benefit of combining 
the treatments (47).

Educational approach of treatment in other studies was not similar to our study. However, the results of studies which applied cognitive behavior therapy, including Hunter et al (47), Christensen et al (48), Krikby (49), Blake et al (50), Ussher et al (51), and Taghizadeh et al (52) were consistent with those of the present study. Nursing interventions play a key role in reducing the symptoms and improving the quality of life of people (42). Studies rooted the family conflicts between teens and parents in insufficient skills in negotiation, disagreement about the rules, responsibilities and values, cognitive distortions, poor skills in problem solving, anger management, decision-making, assertiveness, and communication skills (25).

Those severe, frequent, long conflicts which lead to aggression and business or relationship's disruption require medical interventions (53). Empowering students with anger management skills, relaxation and familiarizing them with PMS changes that lead to mood and physical disorders and promote aggression that has been an important component of consultation content, which can be effective in this regard (46).

- The research unit's reluctance to cooperate, which necessitates the researchers to attempt to persuade the sample units for further cooperation in the implementation of the educational program by explaining the importance of the issue and their participation in the discussion.

- Individual differences in intelligence and learning style could affect their learning potency, so, researchers provided learning contents in a plain language. Furthermore, question and answer and group discussion sessions were designed to enhance their capacity of learning by the researcher and participants.

- The individual differences of the instructor (such as non-identical teaching technique and expression style in various groups in different sessions) were eliminated by using a unique teaching method and implementation. For regular and correct use of tablets, the subjects' address and phone numbers were asked to contact them during the intervention (weekly) and remind them of the importance of the accuracy in taking tablets on time.

- Lack of clarity in questionnaire for the study population was minimized by adding sufficient explanations to the questions.

\section{Conclusion}

In conclusion, in the current study we explored the effect of $M$ officinalis capsules on the intensity of PMS symptoms for three cycles and 6 education sessions in high school girls in Shiraz. The results confirm the effect of the intervention on symptoms improvement and indicate its desirable effects alongside drug treatments on reduction of the intensity of symptoms besides serotonin and dopamine level probably. Since these interventions are cost-effective and no side effects have been reported, this method is suggested to be applied by gynecologists and other health care team members in students healthcounseling centers. In addition, public educational programs should be held and implemented based on these treatment elements at schools and universities.

\section{Conflict of Interests}

Authors declare that they have no conflict of interests.

\section{Ethical Issues}

- The formal letter was obtained from both Shiraz University of Medical Sciences and the high schools' authorities in addition to presenting a full explanation of the study aim.

- Written informed consent was obtained from all the subjects, and they were adequately informed of the study aims and methods.

- The subjects were all assured of the confidentiality of their personal information.

- A private environment was provided for the interview with subjects, completion of the questionnaires, and distribution of the prepared educational pamphlets to the control group.

- This study was registered at the Iranian registry of clinical trials website (identifier: IRCT2014060717998N1; http://en.irct.ir/trial/16427).

\section{Financial Support}

Shiraz University of Medical Sciences, Shiraz, Iran support our study.

\section{Acknowledgements}

This article is a part of Mansoore Dehghani's thesis (No. 926805,). Researchers appreciate Research and Technology Department of Shiraz University of Medical Sciences. The authors would like to thank Shiraz University of Medical Sciences, Shiraz, Iran and also Center for Development of Clinical Research of Nemazee hospital and Dr. Nasrin Shokrpour for editorial assistance.

\section{References}

1. Yarcheski A, Mahon NE, Yarcheski TJ. Anger in early adolescent boys and girls with health manifestations. Nurs Res. 2002;51(4):229-236.

2. Trout KK, Basel-Brown L, Rickels MR, et al. Insulin sensitivity, food intake, and cravings with premenstrual syndrome: a pilot study. J Womens Health (Larchmt). 2008;17(4):657-665. doi:10.1089/jwh.2007.0594

3. Biggs WS, Demuth RH. Premenstrual Syndrome and Premenstrual Dysphoric Disorder. Am Fam Physician. 2011;84(8):918-924.

4. Abraham GE. Nutritional factors in the etiology of the premenstrual tension syndromes. J Reprod Med. 
1983;28(7):446-464.

5. Cunningham J, Yonkers KA, O’Brien S, Eriksson E. Update on research and treatment of premenstrual dysphoric disorder. Harv Rev Psychiatry. 2009;17(2):120-137. doi:10.1080/10673220902891836

6. Braverman PK. Premenstrual syndrome and premenstrual dysphoric disorder. J Pediatr Adolesc Gynecol. 2007;20(1):312. doi:10.1016/j.jpag.2006.10.007

7. Petta CA, Osis MJ, de Padua KS, Bahamondes L, Makuch MY. Premenstrual syndrome as reported by Brazilian women. Int J Gynaecol Obstet. 2010;108(1):40-43. doi:10.1016/j.ijgo.2009.07.041

8. Forrester-Knauss C, Zemp Stutz E, Weiss C, Tschudin S. The interrelation between premenstrual syndrome and major depression: results from a population-based sample. BMC Public Health. 2011;11:795. doi:10.1186/1471-245811-795

9. Wittchen HU, Becker E, Lieb R, Krause P. Prevalence, incidence and stability of premenstrual dysphoric disorder in the community. Psychol Med. 2002;32(1):119-132.

10. Dennerstein L, Lehert P, Heinemann K. Global study of women's experiences of premenstrual symptoms and their effects on daily life. Menopause Int. 2011;17(3):88-95. doi:10.1258/mi.2011.011027

11. Shoairi M, Shojaei P. Students compare the psychological status of female menstruation. J Shahed Uuni 2008;15(76):34-45. [Persian]

12. Fritz MA, Speroff L. Clinical Gynecologic Endocrinology and Infertility. 8th ed. Philadelphia: Lippincott Williams \& Wilkins; 2010

13. He Z, Chen R, Zhou Y, et al. Treatment for premenstrual syndrome with Vitex agnus castus: A prospective, randomized, multi-center placebo controlled study in China. Maturitas. 2009;63(1):99-103. doi:10.1016/j. maturitas.2009.01.006

14. Indusekhar R, Usman SB, O’Brien S. Psychological aspects of premenstrual syndrome. Best Pract Res Clin Obstet Gynaecol. 2007;21(2):207-220. doi:10.1016/j. bpobgyn.2006.10.002

15. Allais G, Castagnoli Gabellari I, Burzio C, et al. Premenstrual syndrome and migraine. Neurol Sci. 2012;33(1):111-115. doi:10.1007/s10072-012-1054-5

16. Bakhshani N, Hasanzadeh Z, Raghibi M. Prevalence of premenstrual symptoms and premenstrual dysphoric disorder among adolescents students of Zahedan. Zahedan J Res Med Sci. 2012;13(8):29-34. [Persian].

17. Bertone-Johnson ER. Vitamin D and the occurrence of depression: causal association or circumstantial evidence? Nutr Rev. 2009;67(8):481-492. doi:10.1111/j.17534887.2009.00220.x

18. Kendler KS, Karkowski LM, Corey LA, Neale MC. Longitudinal population-based twin study of retrospectively reported premenstrual symptoms and lifetime major depression. Am J Psychiatry. 1998;155(9):1234-1240. doi:10.1176/ajp.155.9.1234

19. Steiner M, Pearlstein T, Cohen LS, et al. Expert guidelines for the treatment of severe PMS, PMDD, and comorbidities: the role of SSRIs. J Womens Health (Larchmt). 2006;15(1):5769. doi:10.1089/jwh.2006.15.57

20. Lustyk MK, Gerrish WG, Shaver S, Keys SL. Cognitivebehavioral therapy for premenstrual syndrome and premenstrual dysphoric disorder: a systematic review. Arch Womens Ment Health. 2009;12(2):85-96. doi:10.1007/ s00737-009-0052-y

21. Wong LP, Khoo EM. Menstrual-related attitudes and symptoms among multi-racial Asian adolescent females. Int J Behav Med. 2011;18(3):246-253. doi:10.1007/s12529010-9091-Z

22. Goldberg DP, Gater R, Sartorius N, et al. The validity of two versions of the GHQ in the WHO study of mental illness in general health care. Psychol Med. 1997;27(1):191-197.

23. Werneke U, Goldberg DP, Yalcin I, Ustun BT. The stability of the factor structure of the General Health Questionnaire. Psychol Med. 2000;30(4):823-829.

24. Nazifi M, Mokarami H, Akbaritabar A, Faraji Kujerdi M, Tabrizi R, Rahi A. Reliability, Validity and Factor Structure of the Persian Translation of General Health Questionnire (GHQ-28) in Hospitals of Kerman University of Medical Sciences. J Fasa Univ Med Sci. 2014;3(4):336-342.

25. Ozgoli G, Selselei EA, Mojab F, Majd HA. A randomized, placebo-controlled trial of Ginkgo biloba L. in treatment of premenstrual syndrome. J Altern Complement Med. 2009;15(8):845-851. doi:10.1089/acm.2008.0493

26. Steiner M, Macdougall M, Brown E. The premenstrual symptoms screening tool (PSST) for clinicians. Arch Womens Ment Health. 2003;6(3):203-209. doi:10.1007/ s00737-003-0018-4

27. Kort DH, Lobo RA. Preliminary evidence that cinnamon improves menstrual cyclicity in women with polycystic ovary syndrome: a randomized controlled trial. Am J Obstet Gynecol. 2014;211(5):487.e481-486. doi:10.1016/j. ajog.2014.05.009

28. Gromball J, Beschorner F, Wantzen C, Paulsen U, Burkart M. Hyperactivity, concentration difficulties and impulsiveness improve during seven weeks' treatment with valerian root and lemon balm extracts in primary school children. Phytomedicine. 2014;21(8-9):1098-1103. doi:10.1016/j. phymed.2014.04.004

29. Kennedy DO, Little W, Scholey AB. Attenuation of laboratory-induced stress in humans after acute administration of Melissa officinalis (Lemon Balm). Psychosom Med. 2004;66(4):607-613. doi:10.1097/01. psy.0000132877.72833.71

30. Kennedy DO, Little W, Haskell CF, Scholey AB. Anxiolytic effects of a combination of Melissa officinalis and Valeriana officinalis during laboratory induced stress. Phytother Res. 2006;20(2):96-102. doi:10.1002/ptr.1787

31. van Die MD, Bone KM, Burger HG, Reece JE, Teede HJ. Effects of a combination of Hypericum perforatum and Vitex agnus-castus on PMS-like symptoms in lateperimenopausal women: findings from a subpopulation analysis. J Altern Complement Med. 2009;15(9):1045-1048. doi:10.1089/acm.2008.0539

32. Khayat S, Kheirkhah M, Behboodi Moghadam Z, Fanaei $H$, Kasaeian A, Javadimehr M. Effect of treatment with ginger on the severity of premenstrual syndrome symptoms. ISRN Obstet Gynecol. 2014;2014:792708. doi:10.1155/2014/792708

33. Norman L, Darids G. Psychotropic Drugs. Elsevier Mosby; 2005:517.

34. Cases J, Ibarra A, Feuillere N, Roller M, Sukkar SG. Pilot trial of Melissa officinalis L. leaf extract in the treatment of volunteers suffering from mild-to-moderate anxiety disorders and sleep disturbances. Med J Nutrition Metab. 2011;4(3):211-218. doi:10.1007/s12349-010-0045-4

35. Charles B. Obstetric and Gynecology for Medical Student. 
Baltimore: Lippincott Williams Wilkins; 2001:252-253.

36. Young SN. How to increase serotonin in the human brain without drugs. J Psychiatry Neurosci. 2007;32(6):394-399.

37. Gutknecht L, Jacob C, Strobel A, et al. Tryptophan hydroxylase-2 gene variation influences personality traits and disorders related to emotional dysregulation. Int J Neuropsychopharmacol. 2007;10(3):309-320. doi:10.1017/ s1461145706007437

38. Barefoot J, Gadde K, Helms M, Grichnick K. Combination of stress, Low serotonin may promote heart disease. Duke Health. March 4, 2000. https://corporate.dukehealth.org/ news-listing/combination-stress-low-serotonin-maypromote-heart-disease. Updated January 20, 2016.

39. Sauer WH, Berlin JA, Kimmel SE. Effect of antidepressants and their relative affinity for the serotonin transporter on the risk of myocardial infarction. Circulation. 2003;108(1):3236. doi:10.1161/01.cir.0000079172.43229.cd

40. Salmon E. A review of the literature on neuroimaging of serotoninergic function in Alzheimer's disease and related disorders. J Neural Transm (Vienna). 2007;114(9):11791185. doi:10.1007/s00702-007-0636-5

41. Rapkin AJ, Akopians AL. Pathophysiology of premenstrual syndrome and premenstrual dysphoric disorder. Menopause Int. 2012;18(2):52-59. doi:10.1258/mi.2012.012014

42. 42.Sholehvar F, Takhshid M, Rafiei M. Review of Metabolism, Transport and Role of Serotonin in the Body and the Relation between Serotonin and Diseases. J Fasa Univ Med Sci. 2013;3(1):9-17. [Persian].

43. Halbreich U, O'Brien PM, Eriksson E, Backstrom T, Yonkers KA, Freeman EW. Are there differential symptom profiles that improve in response to different pharmacological treatments of premenstrual syndrome/premenstrual dysphoric disorder? CNS Drugs. 2006;20(7):523-547.

44. Felgentreff F, Becker A, Meier B, Brattstrom A. Valerian extract characterized by high valerenic acid and low acetoxy valerenic acid contents demonstrates anxiolytic activity. Phytomedicine. 2012;19(13):1216-1222. doi:10.1016/j. phymed.2012.08.003

45. Sandford JJ, Argyropoulos SV, Nutt DJ. The psychobiology of anxiolytic drugs. Part 1: Basic neurobiology. Pharmacol Ther. 2000;88(3):197-212.

46. Chau JP, Chang AM. Effects of an educational programme on adolescents with premenstrual syndrome. Health Educ Res. 1999;14(6):817-830.

47. Hunter MS, Ussher JM, Browne SJ, Cariss M, Jelley R, Katz M. A randomized comparison of psychological (cognitive behavior therapy), medical (fluoxetine) and combined treatment for women with premenstrual dysphoric disorder. J Psychosom Obstet Gynaecol. 2002;23(3):193-199.

48. Christensen AP, Oei TPS. The efficacy of cognitive behaviour therapy in treating premenstrual dysphoric changes. J Affect Disord. 1995;33(1):57-63. doi: 10.1016/0165-0327(94)00073-I

49. Kirkby RJ. Changes in premenstrual symptoms and irrational thinking following cognitive-behavioral coping skills training. J Consult Clin Psychol. 1994;62(5):10261032.

50. Blake F, Salkovskis P, Gath D, Day A, Garrod A. Cognitive therapy for premenstrual syndrome: a controlled trial. J Psychosom Res. 1998;45(4):307-318.

51. Ussher JM, Hunter M, Cariss M. A woman-centred psychological intervention for premenstrual symptoms, drawing on cognitive-behavioural and narrative therapy. Clin Psychol Psychother. 2002;9(5):319-331. doi:10.1002/ cpp. 340

52. Taghizadeh Z, Shirmohammadi M, Mirmohammadali M, Arbabi M, Haqqani H. Impact of counseling onsymptoms related premenstrual syndrome. Hayat 2009;15(4):23-34. [Persian].

53. Adams R, Laursen B. The organization and dynamics of adolescent conflict with parents and friends. J Marriage Fam. 2001;63(1):97-110. doi:10.1111/j.1741-3737.2001.00097.x

Copyright $\odot 2018$ The Author (s); This is an open-access article distributed under the terms of the Creative Commons Attribution License (http://creativecommons.org/licenses/by/4.0), which permits unrestricted use, distribution, and reproduction in any medium, provided the original work is properly cited. 